\title{
Accelerated aortic plaque imaging using small field of view imaging and quadruple inversion recovery magnetization preparation
}

Sarah A Peel, Tarique Hussain, Marina Cecelja, Abeera Abbas, Philip Chowienczyk, Matthew Waltham, Gerald Greil, René M Botnar

From 2011 SCMR/Euro CMR Joint Scientific Sessions

Nice, France. 3-6 February 2011

\section{Introduction}

Autopsy data has demonstrated that the abdominal aorta offers a valuable early window for the study of atherosclerosis. Current MRI strategies often suffer from long scan times or require slice gaps. We sought to implement a small field-of-view approach (zoom imaging) (Buecker, A. et al, 1998), to allow complete coverage of the thoracic and abdominal aorta. To improve blood signal nulling before and after contrast administration for identical imaging parameters, we combined zoom imaging with a quadruple inversion recovery (QIR) pre-pulse (Yarnykh, V. et al, 2002).

\section{Purpose}

To demonstrate the feasibility of the novel zoom QIR technique for plaque imaging in the abdominal aorta.

\section{Methods}

The QIR pre-pulse consists of a double inversion recovery (DIR) pre-pulse and a time delay (TI1) followed by a second DIR pre-pulse and a second time delay (TI2). Simulations in MATLAB were performed to study the steady-state longitudinal magnetization of blood $\left(\mathrm{Mz}_{\mathrm{b}}\right)$ for T1 values up to $2000 \mathrm{~ms}$. The effective TR was set to equal the RR-interval for heart-rates between 30 and

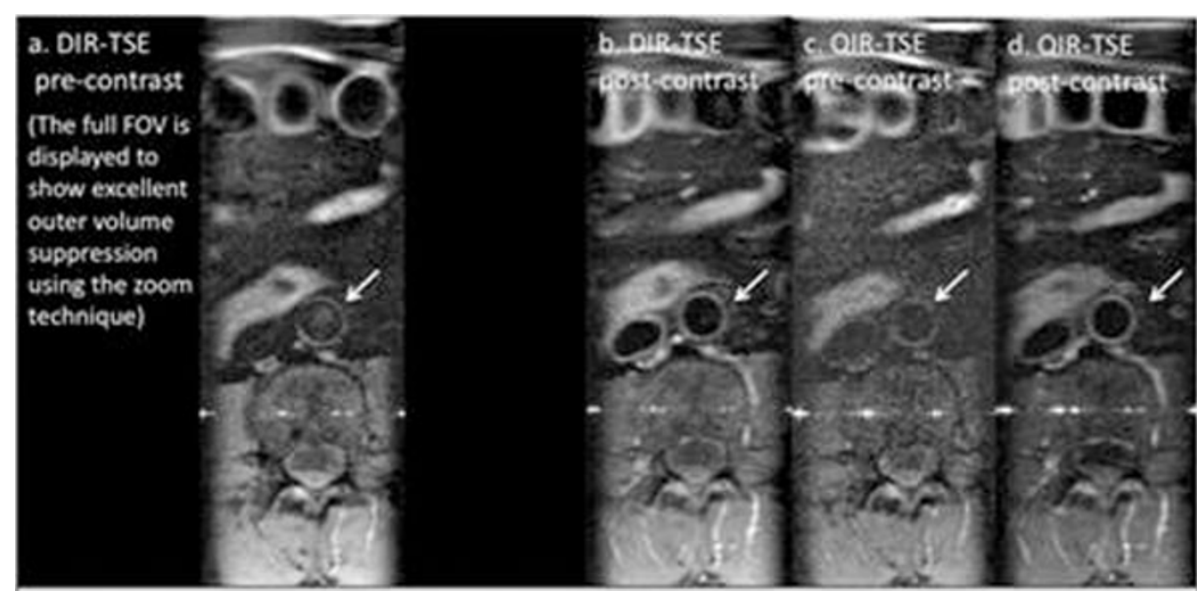

Figure 1 Images of the abdominal aortic wall (arrows) in a healthy volunteer: a. DIR-TSE (pre-contrast). B. DIR-TSE (post-contrast), c. QIR-TSE (precontrast) and d. QIR-TSE (post-contrast). 


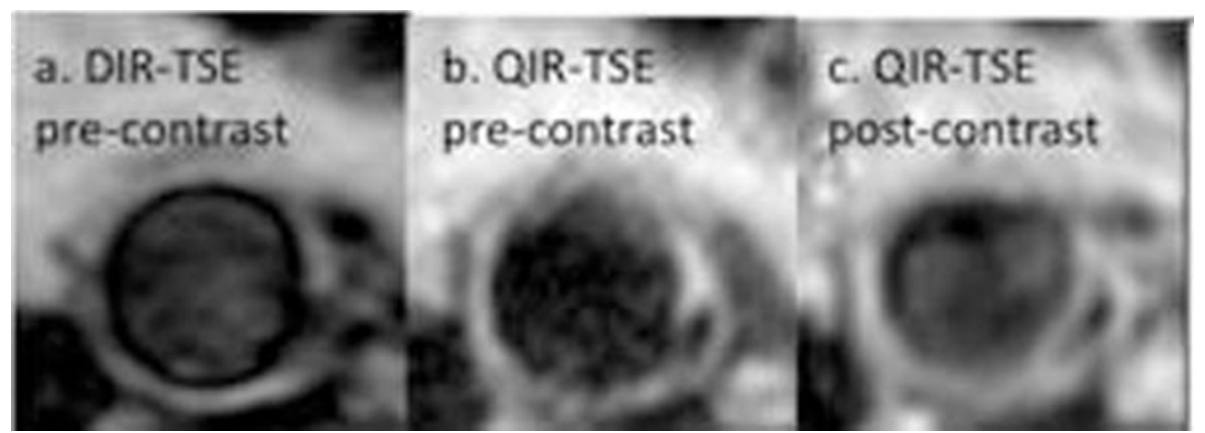

Figure 2 Images of volunteer with a plaque in the abdominal aorta. a. DIR-TSE (pre-contrast), b. QIR-TSE (pre-contrast), c. QIR-TSE (post-contrast).

$120 \mathrm{bpm}$ at 5bpm intervals. For each heart-rate, the optimal TI1 and TI2 values were calculated by minimizing the integral of $\mathrm{Mz}_{\mathrm{b}}$ between 200 and $1400 \mathrm{~ms}$.

Six subjects were imaged on a $1.5 \mathrm{~T}$ scanner using a 32-channel coil. Firstly pre-contrast images were acquired of the abdominal aorta using a $2 \mathrm{D}$ zoom DIR fast spin echo (TSE) sequence (33 slices, slice thickness= $5 \mathrm{~mm}, \mathrm{FOV}=79 \times 201 \mathrm{~mm}$, spatial resolution $=1 \mathrm{mmx} 1 \mathrm{~mm}$, $\mathrm{TE}=5 \mathrm{~ms}, \mathrm{NSA}=2$, shortest trigger delay, imaging every other heartbeat and $\mathrm{TI}=400 \mathrm{~ms}$. Imaging time/slice $\approx 11 \mathrm{~s}$ )

Five selected slices were then imaged with the DIR pre-pulse replaced by the QIR pre-pulse with imaging parameters maintained (except imaging performed every heartbeat, five start-up cycles used to achieve a steadystate and imaging time/slice $\approx 7 \mathrm{~s}$.) Approximately 10-15 minutes after the injection of a double dose of Gadovist, the zoom 2D DIR-TSE and QIR-TSE sequences were repeated in the same five slices.

\section{Results}

Zoom imaging allowed a reduced field-of-view without wrap-around artifact and the QIR pre-pulse achieved blood signal nulling before and after contrast administration using identical imaging parameters in all volunteers (an example is shown in figure 1). One volunteer had an abdominal aortic plaque. The plaque is well defined in QIR-TSE images and there is evidence of post-contrast enhancement (see figure 2).

\section{Conclusions}

The QIR pre-pulse has successfully been combined with ECG gating and zoom imaging. Preliminary data has shown that direct comparison of pre and post contrast imaging of abdominal aortic plaques is feasible.

Published: 2 February 2011
doi:10.1186/1532-429X-13-S1-P368

Cite this article as: Peel et al:: Accelerated aortic plaque imaging using small field of view imaging and quadruple inversion recovery

magnetization preparation. Journal of Cardiovascular Magnetic Resonance 2011 13(Suppl 1):P368.
Submit your next manuscript to BioMed Central and take full advantage of:

- Convenient online submission

- Thorough peer review

- No space constraints or color figure charges

- Immediate publication on acceptance

- Inclusion in PubMed, CAS, Scopus and Google Scholar

- Research which is freely available for redistribution

Submit your manuscript at www.biomedcentral.com/submit
C Biomed Central 